\title{
The role of spirituality and ethics in higher education quality improvement
}

\author{
Masoomeh Labbani Motlagh ${ }^{a^{*}}$, Akhtar Jamali ${ }^{\mathrm{b}}$ and Nader Gholi Ghoorchian ${ }^{\mathrm{c}}$
}

${ }^{a}$ Ph.D Student, Department of Higher Education Administration, Science and Research Branch, Islamic Azad University, Tehran, Iran

${ }^{b}$ Assistant Professor, Department of Higher Education Administration, Science and Research Branch, Islamic Azad University, Tehran, Iran ${ }^{c}$ Professor, Department of Higher Education Administration, Science and Research Branch, Islamic Azad University, Tehran, Iran

\section{H R O N I C L E}

Article history:

Received October 28, 2015

Received in revised format

November 28, 2015

Accepted March 24, 2016

Available online

March 25, 2016

Keywords:

Spirituality

Ethics

Higher Education

Quality Improvement

\section{A B S T R A C T}

\begin{abstract}
This paper aims to examine the role of spirituality and ethics in higher education quality improvement. Two questionnaires were made by the researchers, the first one was completed by heads of departments of Islamic Azad University, Science \& Research Campus, Tehran, Iran $(\mathrm{N} 1=\mathrm{n} 1=200)$ to determine the components of spirituality, ethics and quality improvement (Cronbach's alpha $=0.82)$. The second one was completed by $\mathrm{PhD}$ students $(\mathrm{N} 2=1475$ \& $\mathrm{n} 2=206$ ) in order to find out whether or not there are positive correlations among spirituality, ethics and higher education quality improvement and to determine the role of spirituality and ethics in higher education quality improvement (Cronbach's alpha $=0.85$ ). To ensure the validity of measurement instruments, Structural Equation Modeling (SEM) and Confirmatory Factor Analysis (CFA) were applied. Findings of the research indicated there was a positive correlation among spirituality, ethics and higher education quality improvement.
\end{abstract}

\section{Introduction}

For centuries, universities have been at the forefront in creating and breaking paradigms and educating the future decision-makers, entrepreneurs and leaders. However, universities have remained traditional (Lozano et al., 2013). Universities are also considered as a symbol of countries' development and their human capital (Florida, 2006). Spirituality is the most challenging topic among academic studies (Shahjahan, 2004). Indeed, spirituality has close relationship with human values and creativity and problem solving (Gafoor \& Kotalil, 2011). Spirituality is a new paradigm associated with accountability in higher education so that people's needs would be contented according to a spiritual model. The main motivation in all human beings is spirituality (Fry \& Slucom, 2008; Fernando, et al., 2009). Spirituality is not something that needs to be 'brought into' or 'added onto' the curriculum, it is already at the heart of every subject we teach (Palmer, 2010). Spirituality is considered as a great movement in nowadays organizations (Crossman, 2010; Fry \& Cohen, 2009). Personnel's interests to make human relationships are more important than achieving high career positions (Karakas, 2010;

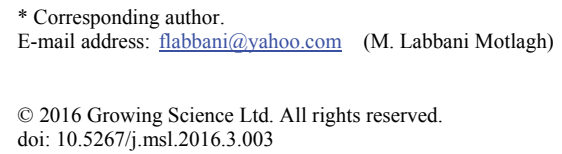


Lips-Wiersma, et al., 2009; Marques, 2010; Rego, et al., 2008). Because spirituality is concerning to a superior power (Pawar, 2009).

To behave ethically means to protect others, reduce harm and increase the sum of good in the world (McAreavey \& Muir, 2011; Ofori, 2009; Eisenbeiss, 2012). Organizations that adhere to ethical precepts have significantly better chances of achieving excellence than those engaged in dishonest and unethical behavior (Procario-Foley, 2002; Baei \& Rahmani, 2015). Ethics includes reasoning, critical thinking, conceptions of right and wrong (values), and related to behavior (Oliver et al., 2011; Nasrabadi \& Arbabian, 2015). They also write nine ethical principles including content competence, pedagogical competence, dealing with sensitive topics, student development, and dual relationships with students, confidentiality, respect for colleagues, valid assessment of students, and respect for the institution.

According to Floyd et al. (2013), students are not learning what they require to compete for the jobs. Siegel and Watson (2013) argue on what students really learn in terms of civic responsibility. Brown and Treviño (2006) believe faculty and students have ethical responsibilities. Four important ethical principles are autonomy, beneficence, justice, and fidelity. Therefore, the organizations which not only believe in spirituality but also nurture it, are converted into driving forces for quality improvement (Gafoor \& Kootalil, 2011). Moreover Fawcett et al. (2008) write; "We know how to invest on technology, but we don't know how to invest on people".

Spirituality and ethics play an important and overlapping role on people's decision making and their success (Duffy \& Blustin, 2005). Since achieving excellence and transcendence have been personal and group purposes of human beings. Spirituality and ethics are the route to achieve excellence in higher education (Mitroff et al., 1999). They also believe in a fourth wave named spiritual-centered organizations which are coming soon. The importance and necessity of the present study is to determine how to achieve quality improvement in higher education through spirituality and ethics approach. Hence it is necessary first to find out the components of spirituality, ethics and quality improvement, and second to determine the role of spirituality and ethics in higher education quality improvement, and third, to show spirituality and ethics have positive correlation with quality improvement.

\section{Literature Review}

The literature suggests a multiplicity of factors that are relevant to understanding the spirituality, ethics and quality improvement in higher education. We will focus on key themes that are considered particularly salient to the descriptive study context. We will review the literature findings. Fallon and Butterfield (2005) summarize the empirical ethical decision-making literature over the period 19962003. Findings show that the overall ethicality of a manager could be predicted by social consensus, magnitude of consequences and likelihood of action. Competition does not influence on ethical decision making. Ethical Culture /Ethical Climate positively affect ethical decision making. Benevolence is the most predominant ethical culture in decision making.

Floyd et al. (2013) write, "Employers conducted for the Association of American Colleges and Universities have found that $75 \%$ of those surveyed felt that colleges and universities need to place greater emphasis on teaching students skills associated with the ability to connect choices and actions to ethical decisions (Hart Research Associates 2010, p. 2). The results show the ability of business schools to self-reflect and self-criticize, with regard to how they teach their students moral values, is more important in the Post-Enron era than it has ever been." World Health Quality Of Life Spirituality Religion Personal Belief Group (2006) relating to World Health Organization examined higher education centers in eighteen countries in Asia, Europe, Africa and the United States of America. They studied how Spirituality, Religion and Personal Beliefs (SRPB) relate to Quality Of Life. But other eight aspects like faith, inner peace, hope, spiritual connection and optimism were added to physical, 
social, psychological and environmental factors. The results of study show that there was a positive correlation between spirituality and positive emotions, social supports, self- esteem, social growth, selfhappiness and self-satisfaction. McSherry et al. (2008) examined the spirituality education of nursing students. They write, "Nursing and Midwifery Council (NMC) Standards of Proficiency for PreRegistration Nursing (2004) has announced, they need skillful nurses to meet spiritual needs of patients". The results of the research focused on necessity of development of spirituality, ethics and cultural aspects of students. The results of their research show that most of the students consider spirituality as meaning, purpose, and self-satisfaction. Moreover the students believe that spirituality overlaps ethics as well. They emphasize on humans' functions which should be in accordance with standards called ethics.

Kuh and Gonyea (2006) applied the information system named "National Survey of Student Engagement" to recognize the relationship among spirituality, education and college experiences. The results of the research show that the students who pray, perform learning activities deeply, interact better with other students, are more satisfied with their universities affairs and have more mutual understanding with people. These students do exercise more than others, pay more attention to cultural events and carry out more social services. Indeed praying, meditation and other similar activities help individual- social development of students.

Bradley and King Kauanui (2003) investigated teachers' spirituality and spiritual culture in a private secular campus, a Christian private campus and a public campus. The research design was in accordance with the study of Mitroff et al. (1999) and Palmer (2010). The results of the study show the difference in spiritual culture of these three campuses and prove that the teachers' spirituality is derived from the existing spiritual culture of their campuses as well. They received the same results as the studies of Mitroff et al. (1999), Palmer (2010), Hassanpour and Mirfallahi (2015) and Salehi et al. (2015). Schmidt-Wilk et al. (2000) studied "Higher Education for Higher Consciousness". The results of their research show that spirituality and ethics aspects were based on human values such as discipline, respect, love, modesty, courage, and intuition, the finest insight experience. The results of the faculties of Maharishi University in Toronto teach the best ideas to improve ethical and spiritual aspects of students. They try to develop excellence values in order to promote human beings' quality of lives.

\section{The proposed study}

The proposed study of this paper presents an empirical investigation to find out the components of spirituality, ethics and quality improvement. In this paper, we study whether or not there is any a positive correlation between spirituality, ethics and higher education quality improvement. We also try to determine the role of spirituality and ethics in higher education quality improvement. After extracting the theories and models of spirituality, ethics and higher education quality improvement, two questionnaires were made by the researchers and the first one completed by heads of departments of Islamic Azad University, Science \& Research Campus, Tehran, Iran $\left(\mathrm{N}_{1}=\mathrm{n}_{1}=200\right)$ to determine the components of spirituality, ethics and quality improvement (Cronbach's alpha $=0.82$ ). The second one was completed by $\mathrm{PhD}$ students $\left(\mathrm{N}_{2}=1475 \& \mathrm{n}_{2}=206\right)$ in order to test the hypothesis of the paper, (Cronbach's alpha=0.85).

To ensure the validity of measurement instruments Structural Equation Modeling (SEM) and Confirmatory Factor Analysis (CFA) were applied. Findings of the research, showed there was a positive correlation between spirituality, ethics and higher education quality improvement and the hypothesis of the study was not rejected $(t=7.25$, Sig. $=0.000)$. Path way analysis results in the mode of meaningful model, confirmed the meaningfulness of this relationship. Considering the necessity of continues quality improvement in higher education inside-out spiritual and ethics change of people were the most important priority with coefficient 1 , which was determined by higher education experts and $\mathrm{PhD}$ students. Customer orientation with coefficient 0.33 was the weakest point of continues 
quality improvement in higher education. To take into consideration of the received coefficient, teachers' spirituality and ethics were reflected from spiritual culture of their faculty. The proposed study of this paper considers three following questions and one hypothesis;

1-What are the components of spirituality and ethics in higher education?

2-What are the components of quality improvement in higher education?

3-What is the role of spirituality and ethics in higher education quality improvement?

Hypothesis: Spirituality and ethics have positive effect on higher education quality improvement.

Customers are considered as essential assets in any organizations (Azad \& Hashemi, 2013; Sales et al., 2015). Most of Excellence Models (Ems) and National Quality Awards (NQAs) are introduced in the last 1980's and 1990's. Ems and NQAs measure the degree of excellence. The models inherently are dynamic (Tawler, 2009, Toroudi, et al., 2015). According to Tawler (2009) human values are considered in excellence models. Sarasat (2005) introduced fourteen principles of human values as follows: 1-Braveness; 2-Good Will; 3-Knowledge Learning; 4-Benevelonce; 5-Self-Control; 6-Work Without selfishness; 7-Self- Learning; 8-Life with Discipline; 9-Kindness; 10-Non-Violence; 11Telling the Truth; 12-Peaceful mind; 13-Friendship; and 14-Modesty. Tawler (2009) reached the conclusion that most of major values and human values were common. Major values of Excellent Models are derived from Human Values. Table 1 shows the Major Values/ the first principles of Excellence Model.

\section{Table 1}

The Major Values/ The First Principles of Sixteen Excellence Models (Trawler, 2009)

\begin{tabular}{ll}
\hline Human Values & Major Values of Excellence Models \\
Braveness & Leadership and Purpose Constancy \\
\hline Integrity and Good Will & Emphasis on Quality / Customer \\
\hline Continuous Knowledge Learning & Continuous Learning, Innovation and Development \\
\hline Emotions Control & Personnel Participation and Development \\
Loyalty and Work Without Selfishness & Development of Participation \\
Self-Learning and Knowledge Division & Agility \\
Self-Regulating & Emphasizing on Future \\
Uprightness & Social Responsibility \\
Non-injuriousness & Emphasis on Results : Creating Value Systems \\
Honesty & Process and Truth- Center Management \\
Non-Violence & Cooperation/Team Working/Faster Response \\
Ignorance & Understanding the Differences \\
Peace & Ration Elimination \\
Doing the best & Mottos Elimination \\
Respect and Being kind to all Creatures & Education and Reinstructing \\
Not being greedy for More Power & Knowledge Management \\
Creativity & Individual and Organizational learning \\
Modesty & Advocating of Globalization \\
Calmness & Lack of Terror \\
\hline
\end{tabular}

\section{Results}

Question 1: What are components of Spirituality and Ethics in Higher Education?

Data gathered from Spirituality and Ethics in Higher Education questionnaire was analyzed. Table 2 shows mean, standard deviation, variance, minimum and maximum marks of Spirituality and Ethics. 


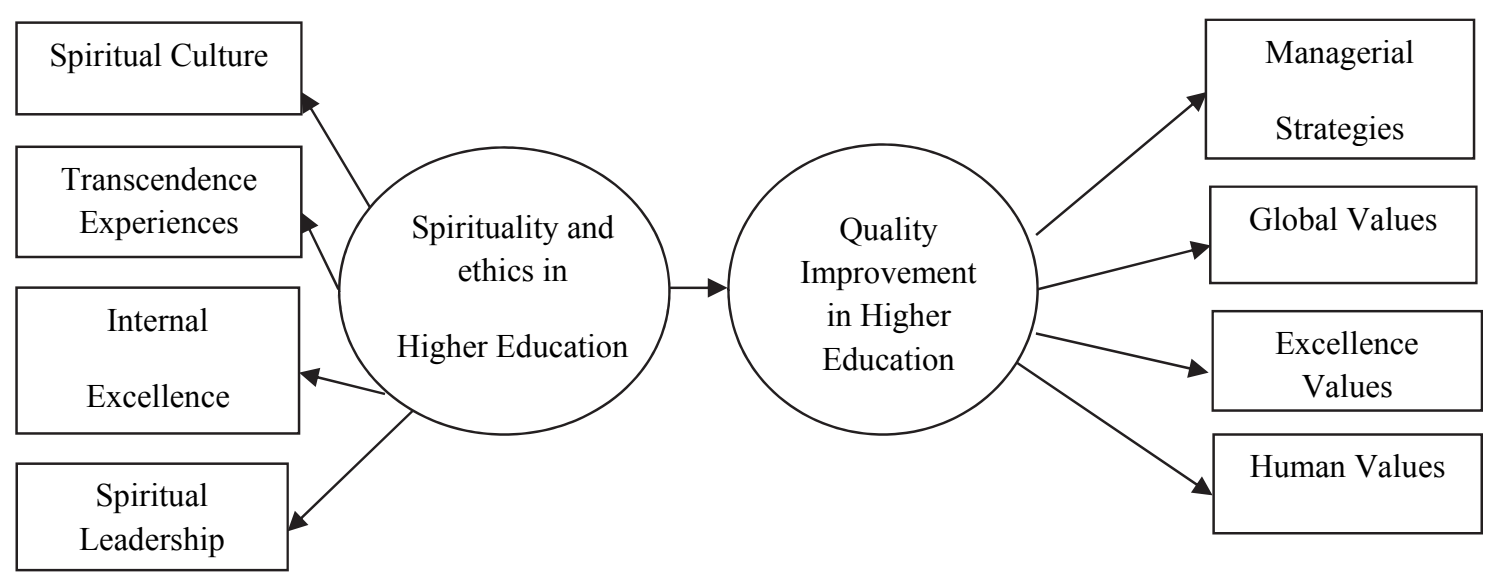

Fig. 1. The components of spirituality, ethics and higher education quality improvement

Table 2

Mean, Median, Standard Deviation of Minimum and Maximum of Spirituality and Ethics Construct and Their Indicators Separately $\left(\mathrm{N}_{1}=\mathrm{n}_{1}=200\right)$

\begin{tabular}{lccccll}
\hline Indicator & Mean & Median & Standard Deviation & Variance & Min & Max \\
\hline 1-Spiritual Leadership & 157.3592 & 150.000 & 75.65478 & 5723.646 & 9.00 & 345.00 \\
2-Transcendece Experiences & 150.2136 & 135.0000 & 76.00560 & 5776.852 & 3.00 & 34.00 \\
3-Inner Excellence & 1.4844 & 1.4000 & 6.8429 & 4.683 & 15.00325 .00 \\
4-Spiritual Culture & 200.1651 & 200.0250 & 20.2941 & 30.48228 & 18.00245 .00 \\
5-Spirituality Construct & 572.5243 & 530.0000 & 20.48228 & 40.162 & 45.00180 .00 \\
\hline
\end{tabular}

In Fig. 2; Left rectangles show hidden factors and right rectangles show measuring variables related to those factors. Ovals show the size of expressed variance for each variable. More over the comparison of Spiritual Culture indicators using the variance analysis tests showed that there is a meaningful difference between these indicators. The most mean has been related to Spiritual Leadership and the least mean has been related to Spiritual Culture.

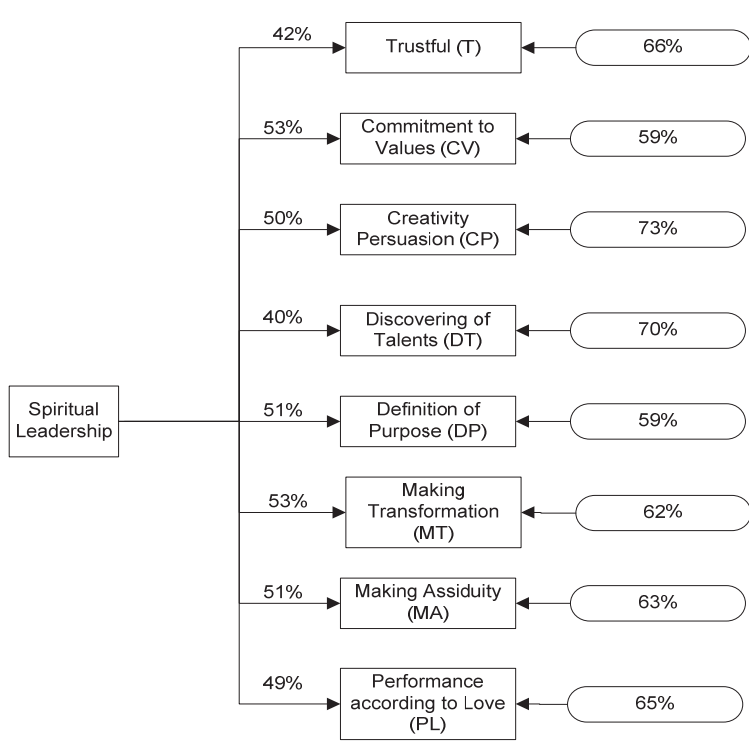

Fig. 2. Factor Analysis Model of hidden variable named Spiritual Leadership (The first indicator of Spirituality and Ethics in Higher Education)

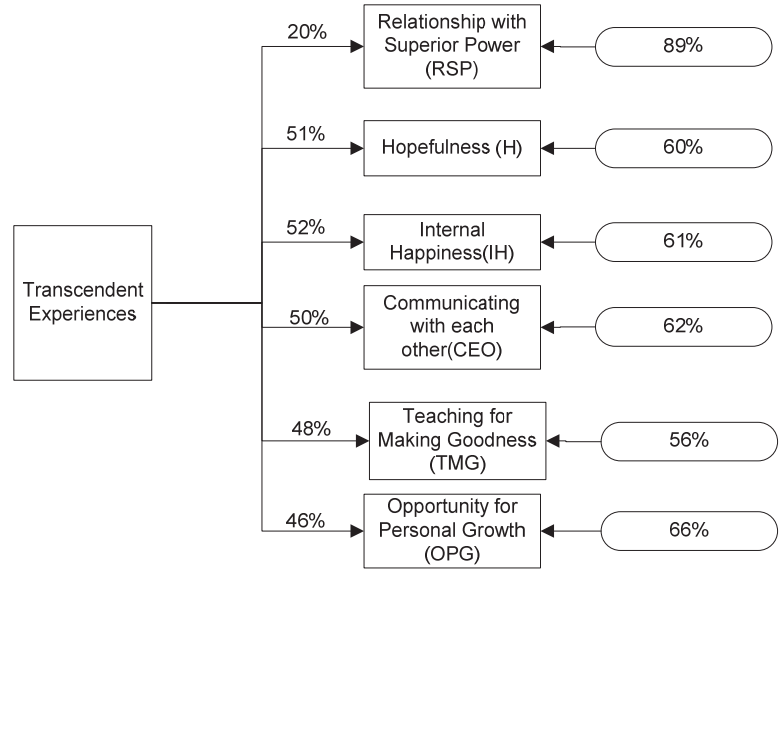

Fig. 3. Factor Analysis Model of hidden variable named Transcendent Experiences (The second indicator of Spirituality and Ethics in Higher Education) 


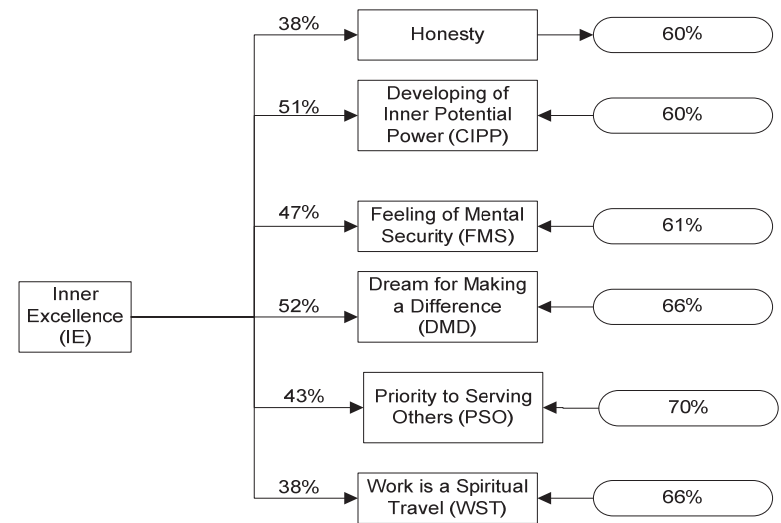

Fig. 4. Factor Analysis Model of hidden variable named Inner Excellence (The third indicator of Spirituality and Ethics in Higher Education)

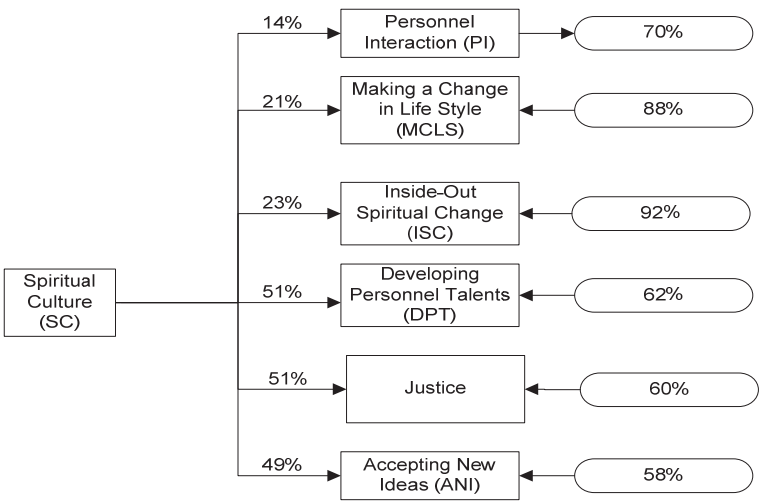

Fig. 5. Factor Analysis Model of hidden variable named Spiritual Culture (The fourth indicator of Spirituality and Ethics in Higher Education)

Question 2: What are components of Quality Improvement in Higher Education?

Data gathered from Quality Improvement in Higher Education questionnaire was analyzed. Table 3 shows mean, standard deviation, variance, minimum and maximum marks of Quality Improvement construct.

\section{Table 3}

Mean, Median, Standard Deviation of The Minimum and Maximum of Quality Improvement Construct and Their Indicators Separately $\left(\mathrm{N}_{1}=\mathrm{n}_{1}=200\right)$

\begin{tabular}{lcccccc}
\hline Indicator & Mean & Median & Standard Deviation & Variance & Minimum & Maximum \\
\hline 1-Management & 20.758 & 20.6000 & 10.7824 & 30.057 & 45.00 & 370.00 \\
2-Human Values & 170.1650 & 165.0000 & 89.30901 & 6774.773 & 21.00 & 395.00 \\
3- Excellence Values & 185.5874 & 160.0000 & 84.32191 & 7110.185 & 9.00 & 365.00 \\
4-Wourld Values & 173.2233 & 18.000 & 78.77302 & 6205.189 & 11.00 & 35.00 \\
5-Quality Construct & 20.0485 & 20.9000 & 20.8975 & 40.395 & 107.00 & 1435.00 \\
\hline
\end{tabular}

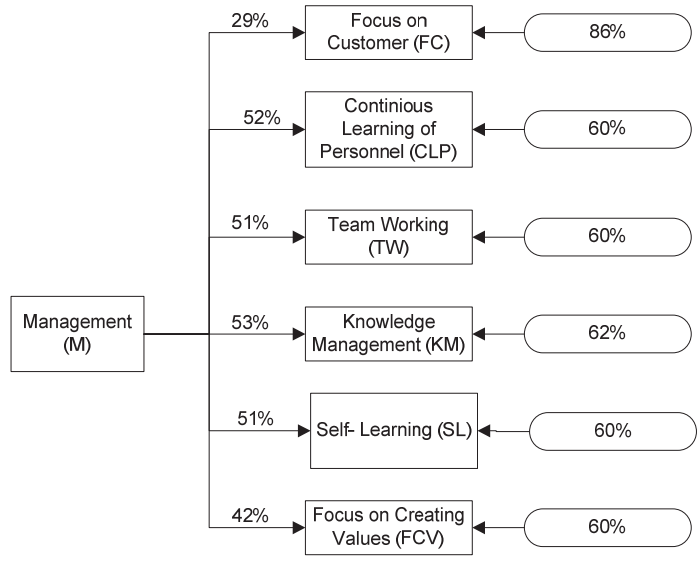

Fig. 6. Factor Analysis Model of hidden variable named Management (The first indicator of Quality Improvement in Higher Education)

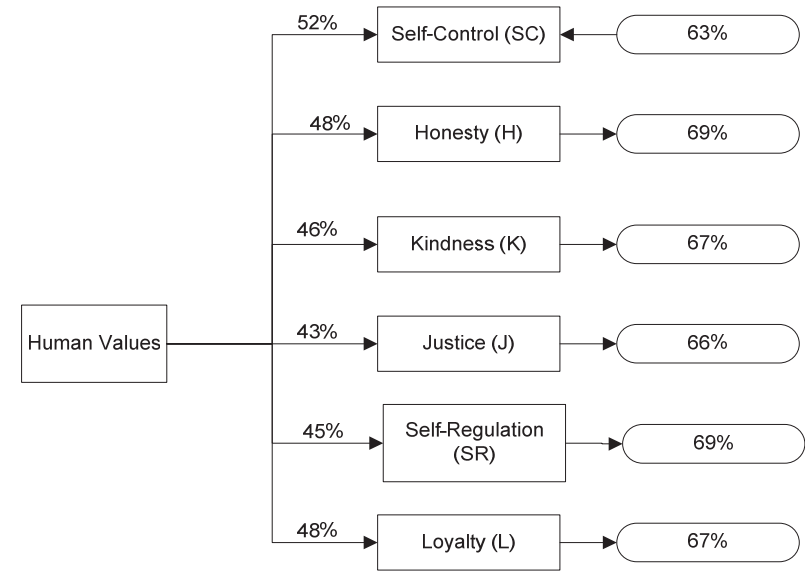

Fig. 7. Factor Analysis Model of hidden variable named Human Values (The second indicator of Quality Improvement in Higher Education) 


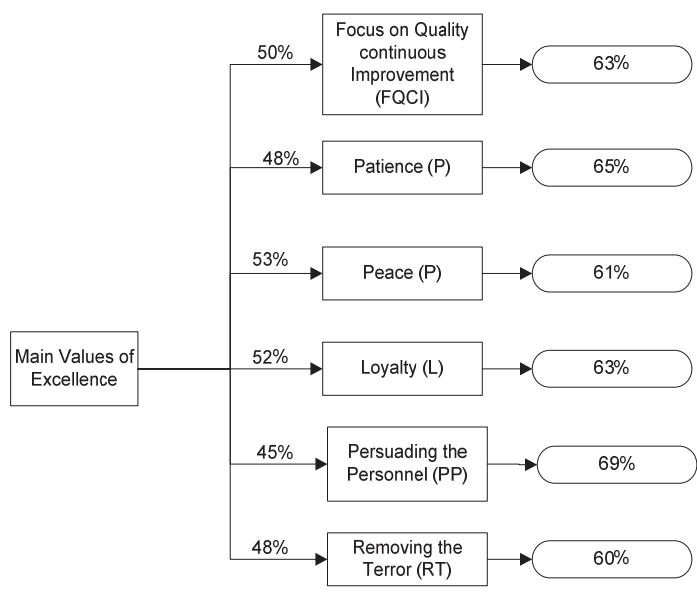

Fig. 8. Factor Analysis Model of hidden variable named Main Values of Excellence (The third indicator of Quality Improvement in Higher Education)

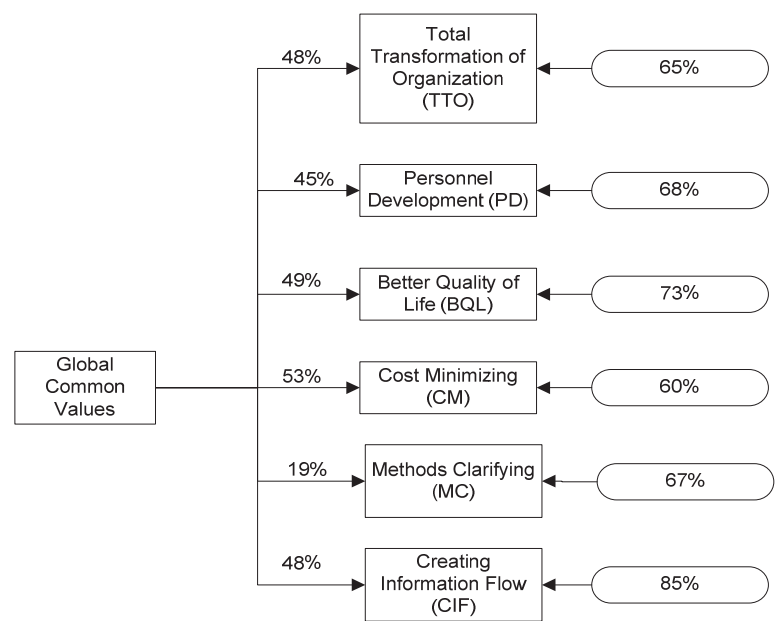

Fig. 9. Factor Analysis Model of hidden variable named Global common Values (The fourth indicator of Quality Improvement in Higher Education)

Question 3-What is the role of spirituality and ethics in higher education quality improvement?

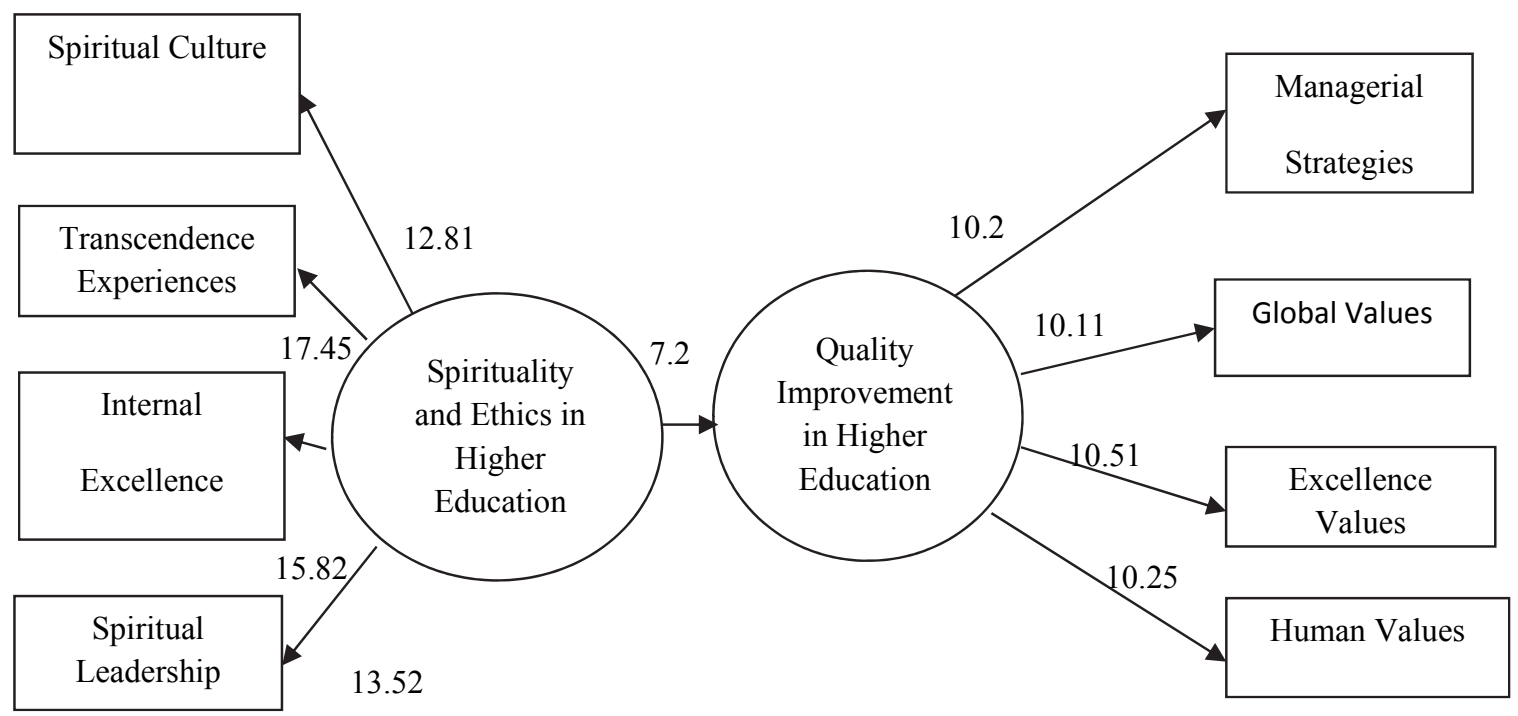

Fig. 10. $t$ value Model: Spirituality and Ethics have positive effects on Quality improvement

Hypothesis: Spirituality and ethics have positive effects on higher education quality improvement. Findings of the research indicate, there is a positive correlation between spirituality, ethics and higher education quality improvement and the hypothesis of the study was not rejected $(t=7.25$, Sig. $=0.000)$. Path way analysis results in the mode of meaningful model, confirmed the meaningfulness of this relationship.

\section{Discussion and Conclusion}

In this paper, we have presented an empirical investigation to examine the role of spirituality and ethics in higher education quality improvement. The study has designed two questionnaires by the researchers where the first one completed by the heads of departments of Islamic Azad University, Science \& Research Campus, Tehran, Iran to determine the components of spirituality, ethics and quality improvement. Furthermore the second one was completed by $\mathrm{PhD}$ students in order to test the 
hypothesis of the paper to determine whether or not there is a positive correlation between spirituality, ethics and higher education quality improvement and to determine the role of spirituality and ethics in higher education quality improvement. Findings of the research, showed there were positive correlations among spirituality, ethics and higher education quality improvement. In addition, spirituality and ethics had positive effects on higher education quality improvement. The results of this survey on spiritual leadership were consistent with other findings in the study (Duffy \& Blustin, 2005; Shahjahan, 2004; Crossman, 2010; Eisenbeiss,2012; Lozano et al., 2013; Fernando et al., 2009; Carver Sekers, 2008; Fry et al., 2009; Brown et al. 2006). In addition the results about spiritual culture were consistent with other findings (Bradly et al., 2003; Mitroff \& Denton, 1999; Palmer, 2010; Tissdell, 2003; Mc Sherry et al., 2008; Ofori, 2009; Salehi et al., 2015; Fawcett et al., 2008). Moreover the results about transcendence experiences were consistent with other findings (World Health Quality Of Life Spirituality Religion Personal Belief Group, 2006; Floyd et al., 2013; Fallon's Report, 2005; Seigel et al., 2013; McAreavey et al., 2011; Karakas, 2010; Chattopadhyay, 2010; Mitroff et al., 1999; Procario-Foley et al., 2002). The results of study about excellence were consistent with other findings (Tawlar, 2009; Toroudi et al., 2015; Sales et al., 2015; Naserabadi, 2015). According to the results of our survey spirituality and ethics overlap human values as well. Higher education' administrators must take seriously their obligation to contribute spiritual and ethical development of students via establishing appropriate infrastructures to improve the quality and achieve excellence.

\section{References}

Azad, N., \& Hashemi, S. (2013). A study on important factors influencing customer relationship management: A case study of Mobile service provider. Management Science Letters, 3(4), 11611166.

Baei, S., \& Rahmani, Z. (2015). The effect of unethical behavior on brand equity. Management Science Letters, 5(6), 603-610.

Bradley, J., \& King Kauanui, S. (2003). Comparing spirituality on three southern California college campuses. Journal of Organizational Change Management, 16(4), 448-462.

Brown, M. E., \& Treviño, L. K. (2006). Ethical leadership: A review and future directions. The leadership quarterly, 17(6), 595-616.

Crossman, J. (2010). Conceptualising spiritual leadership in secular organizational contexts and its relation to transformational, servant and environmental leadership. Leadership \& Organization Development Journal,31(7), 596-608.

Chattopadhyay, D. (2010). A Study of Inter-Relationships Among Spirituality, Human Values \& Ethics and Its Association With Ethical Values of Corporate Governance. In AIMS Interactional Conference on Value-based Management.

Duffy, R. D., \& Blustein, D. L. (2005). The relationship between spirituality, religiousness, and career adaptability. Journal of Vocational Behavior, 67(3), 429-440.

Eisenbeiss, S. A. (2012). Re-thinking ethical leadership: An interdisciplinary integrative approach. The Leadership Quarterly, 23(5), 791-808.

Fallon, M. J., \& Butterfield, K. D. (2005). A review of the empirical ethical decision-making literature: 1996-2003. Journal of business ethics, 59(4), 375-413.

Fawcett, S. E., Brau, J. C., Rhoads, G. K., Whitlark, D., \& Fawcett, A. M. (2008). Spirituality and organizational culture: Cultivating the ABCs of an inspiring workplace. International Journal of Public Administration, 31(4), 420-438.

Fernando, M., Beale, F., \& Geroy, G. D. (2009). The spiritual dimension in leadership at Dilmah Tea. Leadership \& Organization Development Journal,30(6), 522-539.

Florida, R. (2006). Regions and universities together can foster a creative economy. Chronicle of Higher Education, 53(4), B6.

Floyd, L. A., Xu, F., Atkins, R., \& Caldwell, C. (2013). Ethical outcomes and business ethics: Toward improving business ethics education. Journal of business ethics, 117(4), 753-776. 
Fry, L. W., \& Slocum, J. W. (2008). Maximizing the triple bottom line through spiritual leadership. Organizational Dynamics, 37(1), 86-96.

Fry, L. W., \& Cohen, M. P. (2009). Spiritual leadership as a paradigm for organizational transformation and recovery from extended work hours cultures. Journal of Business Ethics, 84(2), 265-278.

Gafoor, K. A., \& Kottalil, N. K. (2011). Cultivating the spirit through resilience: Vision of effective schools and mission of caring teachers. Online Submission.

Hassanpour, A., \& Mirfallahi, S. (2015). The impact of culture and strategic orientation on service innovation capability: Evidence from banking industry. Management Science Letters, 5(12), $1047-$ 1052.

Karakas, F. (2010). Spirituality and performance in organizations: A literature review. Journal of business ethics, 94(1), 89-106.

Kuh, G. D., \& Gonyea, R. M. (2006). Spirituality, liberal learning, and college student engagement. Liberal Education, 92(1), 40-47.

Lips-Wiersma, M., Dean, K. L., \& Fornaciari, C. J. (2009). Theorizing the dark side of the workplace spirituality movement. Journal of Management Inquiry, 18(4), 288-300.

Lozano, R., Lukman, R., Lozano, F. J., Huisingh, D., \& Lambrechts, W. (2013). Declarations for sustainability in higher education: becoming better leaders, through addressing the university system. Journal of Cleaner Production, 48, 10-19.

Marques, J. F. (2010). Spiritually or politically driven behavior: differences in the workplace. Development and Learning in Organizations: An International Journal, 24(6), 12-16.

McSherry, W., Gretton, M., Draper, P., \& Watson, R. (2008). The ethical basis of teaching spirituality and spiritual care: A survey of student nurses perceptions. Nurse Education Today, 28(8), 10021008.

McAreavey, R., \& Muir, J. (2011). Research ethics committees: values and power in higher education. International Journal of Social Research Methodology, 14(5), 391-405.

Mitroff, I. I., Mitroff, I., Denton, E. A. (1999). A spiritual audit of corporate America: A hard look at spirituality, religion, and values in the workplace (Vol. 140). Jossey-Bass

Nasrabadi, A., Arbabian, A. (2015). The effects of professional ethics and commitment on audit quality. Management Science Letters, 5(11), 1023-1028.

Ofori, G. (2009). Ethical leadership: Examining the relationships with full range leadership model, employee outcomes, and organizational culture. Journal of Business Ethics, 90(4), 533-547.

Oliver, D., Nusbaum, E., \& Emily Nusbaum, Pitt, J. (2011). Applying an ethical decision-making model across the curriculum in higher education administration, special education, and rehabilitation counseling pedagogy. Chapman University Emerging Scholars Conference September 23-24, 2011.

Palmer, P. J. (2010). The courage to teach: Exploring the inner landscape of a teacher's life. John Wiley \& Sons.

Pawar, B. S. (2009). Individual spirituality, workplace spirituality and work attitudes: An empirical test of direct and interaction effects. Leadership Organization Development Journal, 30(8), 759.

Procario-Foley, E. G., \& Bean, D. F. (2002). Institutions of higher education: Cornerstones in building ethical organizations. Teaching Business Ethics, 6(1), 101-116.

Rego, A., \& Pina e Cunha, M. (2008). Workplace spirituality and organizational commitment: an empirical study. Journal of Organizational Change Management, 21(1), 53-75.

Salehi, S., Mirsepasi, N., \& Farhangi, A. (2015). Investigating organizational culture adaptability of broadcasting firm in response to environmental changes. Management Science Letters, 5(11), 975 978.

Sales, J., Baybordi, A., Aydenlu, M., Asaldoost, N. (2015). Measuring effect of managerial ability on earning quality. Management Science Letters, 5(9), 821-826.

Schmidt-Wilk, J., Heaton, D. P., \& Steingard, D. (2000). Higher education for higher consciousness: Maharishi University of Management as a model for spirituality in management education. Journal of Management Education,24(5), 580-611. 
Shahjahan, R. A. (2004). Centering spirituality in the academy toward a transformative way of teaching and learning. Journal of Transformative Education, 2(4), 294-312.

Siegel, B. L., \& Watson, S. C. (2013). Terms of the contract: The role of ethics in higher education. Journal of Executive Education, 2(1), 7.

Talwar, B. (2009). Comparative study of core values of excellence models vis-à-vis human values. Measuring Business Excellence, 13(4), 34-46.

Toroudi, H., Alamdardehi, S., Mahjoub, N., \& Ardestani, A. (2015). An application of organizational excellence assessment: Evidence from cement industry. Management Science Letters, 5(11), 979982.

WHOQOL SRPB Group. (2006). A cross-cultural study of spirituality, religion, and personal beliefs as components of quality of life. Social Science \& Medicine, 62(6), 1486-1497.

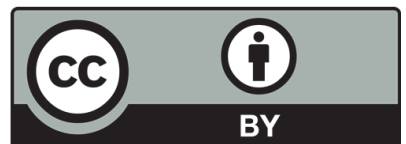

(C) 2016 by the authors; licensee Growing Science, Canada. This is an open access article distributed under the terms and conditions of the Creative Commons Attribution (CC-BY) license (http://creativecommons.org/licenses/by/4.0/). 